\title{
Three-Component Multi-Catalytic Enantioselective Oxa-Michael/ Aldolization Sequence and Application to (+)-Yashabushitriol Synthesis
}

\author{
Céline Sperandio, ${ }^{[\mathrm{a}]}$ Jean Rodriguez, ${ }^{[\mathrm{a}]}$ and Adrien Quintard*[a] \\ Dedicated to the memory of Prof. Dieter Enders
}

Abstract: By a selective three-component multi-catalytic sequence, amino-catalyzed oxa-Michael addition of oximes to $\alpha, \beta$-unsaturated aldehydes has been combined with a coppercatalyzed decarboxylative aldolization. This one-pot procedure enables the rapid construction of functionalized ketodiol scaffolds in 85 to $94 \%$ ee. Simple reduction of both the resulting oxime and ketone functions delivered the corresponding 1,3,5triols of interest in a minimum of steps while considerably limiting waste generation. This methodology has been applied to the shortest (4 steps) synthesis of (+)-yashabushitriol, highlighting the synthetic potential of this new multi-catalytic sequence.
Polyketides are ubiquitous in natural products and drugs with unique properties resulting from their ability to form selective hydrogen-bonding frameworks (Figure 1). ${ }^{[1]}$ Therefore, the discovery of efficient and selective methods for the preparation of such complex organic scaffolds has exalted scientific curiosity for decades. ${ }^{[2]}$ However, despite the considerable progress observed in catalytic enantioselective synthesis notably through

[a] C. Sperandio, Prof. J. Rodriguez, Dr. A. Quintard

Aix Marseille Univ, CNRS, Centrale Marseille, iSm2,

Marseille, France

E-mail: adrien.quintard@univ-amu.fr

https://ism2.univ-amu.fr/fr/annuaire/stereo/quintardadrien

Supporting information and ORCID(s) from the author(s) for this article are (D) available on the WWW under https://doi.org/10.1002/ejoc.202000185. aldolization, ${ }^{[3]}$ the rapid construction of such challenging acyclic motifs is still most of the time based on lengthy stepwise processes. In order to minimize the number of steps necessary to create the crucial alcohol backbones, different enantioselective cascade reactions have been successfully developed in the last years. ${ }^{[4]}$ Most notably, strategies based on multiple aldolization $^{[5]}$ or allylation ${ }^{[6]}$ events have considerably decreased the number of operations required for the preparation of a broad range of valuable extended 1,3-polyols motifs.

However, these strategies still suffer from drawbacks such as undesired substrate preactivation, limited scope or stepwise transformation of the cascade adducts to advance towards the desired final polyols. As a result, the discovery of innovative approaches enabling the direct elaboration of enantioenriched

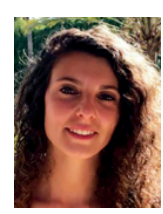

Céline Sperandio studied chemistry at Aix-Marseille university where she graduated with a Master degree in 2016. She then performed her doctoral studies under the direction of Adrien Quintard and obtained her PhD in 2019. Her research interests encompass the development of catalytic reactions and the study of new polyols supramolecular properties.

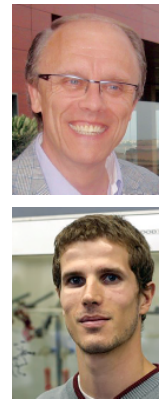

Jean Rodriguez studied chemistry at the University of Aix-Marseille (France) where he completed his Ph.D. as a CNRS researcher with Prof. B. Waegell and Prof. P. Brun in 1987. He completed his Habilitation in 1992, also at Marseille, where he is currently Professor and Director of the UMRCNRS-7313-iSm2. His research interests include the development of domino and multicomponent reactions, and their application in stereoselective organocatalyzed synthesis. In 1998 he was awarded the ACROS prize in Organic Chemistry, in 2009 he was awarded the prize of the Division of Organic Chemistry from the French Chemical Society and in 2013 became "Distinguished member" of the French Chemical Society.

Adrien Quintard discovered chemistry at the technical institute of Castres from University Toulouse III before obtaining a Master degree in 2007 at Lyon (CPE Lyon/University Lyon I). He then moved to Geneva for a PhD obtained in 2011 for his work on metal-and organo-catalysis with Prof. Alexandre Alexakis. After a first Postdoc with Prof. Barry Trost at the university of Stanford, he joined Marseille in 2012 for a second Postdoc before obtaining in 2013 an ANR starting grant to initiate a new research program on multi-catalysis. He subsequently entered the CNRS as a senior researcher in 2014 with research interests encompassing a broad range of areas of organic chemistry (catalysis, synthesis, supramolecular chemistry). Recently, his contribution was recognized by the award of the young researcher "Emergence" prize from the Organic Division of the French Chemical Society and he also obtained a Thieme Chemistry Journals award. 


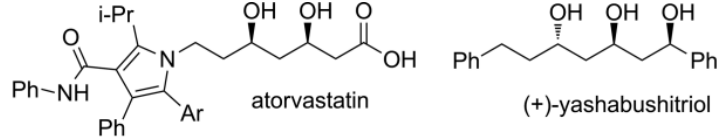

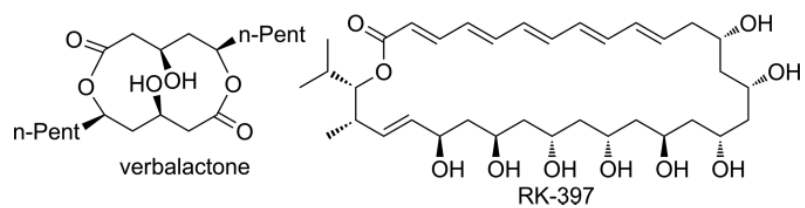

Figure 1. Examples of 1,3-polyols containing molecules.

polyketides scaffolds possessing the appropriately installed functions is highly desirable and still represents a daunting challenge.

An ideal synthetic route should rapidly assemble simple building blocks directly into the appropriate polyol structure. In this context, we hypothesized that $\alpha, \beta$-unsaturated aldehydes could act as pivotal fragments for a cascade oxa-Michael addition/aldolization (Scheme 1.a). ${ }^{[7]}$ After ketone reduction and through the use of appropriate catalysts, this strategy should enable in a straightforward manner the enantioselective preparation of 1,3,5-triols with obvious implications in natural products synthesis.

a) Proposed 1,3-polyols synthesis:
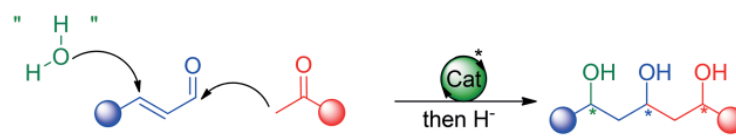

b) Multi-catalytic oxa-Michael/aldolization (this work):

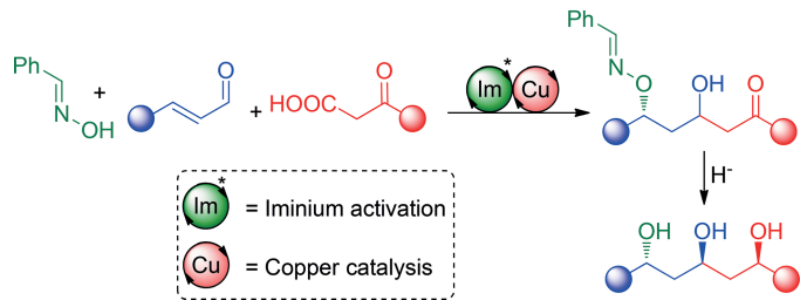

Scheme 1. Proposed strategy for the rapid synthesis of 1,3,5-triols.

In order to develop such a strategy, efficient and compatible catalytic events should be suitably combined. Most notably, given the known poor stability of the intermediate oxa-Michael adducts, ${ }^{[8]}$ an aldolization method occurring rapidly and under mild conditions is mandatory to intercept these species and to irreversibly form the final adduct. To this end, we propose a multi-catalytic sequence combining the known amino-catalyzed oxa-Michael addition of oximes to $\alpha, \beta$-unsaturated aldehydes ${ }^{[\mathrm{a}, 8 \mathrm{~b}]}$ with a copper-catalyzed decarboxylative aldolization (Scheme 1.b). ${ }^{[9,10]}$ Simple reduction of both the resulting oxime and ketone functions would generate the desired 1,3,5-triols in a minimum of steps while considerably limiting waste generation. Herein, we present our efforts at developing the proposed transformation in a multi-component fashion and applying it to the only 4 steps synthesis of (+)-yashabushitriol.
We first focused on the identification of a suitable catalyst for the challenging aldolization that should be able to consume the oxa-Michael adduct efficiently (Table 1). After reacting for 4 hours oxime $\mathbf{1} \mathbf{a}$, pentenal $(\mathbf{2} \mathbf{a})$, in the presence of diarylprolinol silyl ether (S)-cat-1 and benzoic acid, ketoacid 3a and different second catalysts (cat-2) were directly added to the reaction mixture. It must be pointed out that the low stability of the intermediate oxa-Michael adducts makes it mandatory to perform the one-pot aldolization without isolation of this sensitive intermediate.

Table 1. Optimization of the oxa-Michael/aldolization

$(\mathbf{S})$-cat-1 $(10 \mathrm{~mol} \%)$
thCOOHe, $\left(10 \mathbf{m o l}^{\circ} \mathrm{C}, 4 \mathrm{~h}\right.$

[a] Isolated yield after column chromatography. [b] $d r$ determined by ${ }^{13} \mathrm{C}$ NMR after column chromatography. [c] Enantiomeric excess determined by chiral HPLC after column chromatography. [d] Reaction performed using $\mathbf{1 b}$ instead of 1a. nd = not determined.

As for previous examples of aldol reactions on sensitive substrates, ${ }^{[11]}$ use of various tertiary amine organocatalysts ${ }^{[12]}$ did not provide interesting levels of reactivity mainly decomposing the intermediate oxa-Michael adduct potentially through retrooxa-Michael (entries 1-2). For example, using quinine, the final adduct was isolated in only 9\% yield and 1.3:1 $d r$ (94 and 84\% ee). With these initial results, we next turned our attention to the use of Lewis acids as compatible catalysts for the aldolization. ${ }^{[1]]}$ Applying $\mathrm{NiCl}_{2}, \mathrm{MgBr}_{2}, \mathrm{FeCl}_{3}, \mathrm{ZnBr}_{2}$ complexes did not provide any formation of the desired aldolization product (entries 3-6).

Turning to different copper complexes restored the reactivity in this aldolization. Use of $\mathrm{Cu}(\mathrm{OTf})_{2}$ considerably improved the results forming 4 in a promising $40 \%$ yield and $92 \%$ ee (entry 7). It must be pointed out that the first stereocenter generated during the oxa-Michael addition is poorly discriminating over the second one providing 4 in 1:1 dr. ${ }^{[13]}$ While $\mathrm{Cu}(\mathrm{acac})_{3}$ reduced the yield to $30 \%$ (entry 8 ), use of $\mathrm{Cu}$ (isobutyrate) $)_{2}$ improved the reactivity generating the desired product in optimum 58\% yield, 1.1:1 $d r$ and $>92 \%$ ee (entry 9). Changing from 
copper to $\mathrm{Fe}(\mathrm{acac})_{3}$ slightly improved the diastereocontrol albeit at the expense of the reactivity forming 4 in $43 \%$ yield and 1:3 dr (entry 10). In addition, minor racemization of the oxa-Michael intermediate must occur since the product is isolated with this catalyst in $90 \% \mathrm{ee}$. A final attempt to improve the diastereocontrol was performed using pyridine containing oxime $\mathbf{1 b}$ (entry 11). However, even though the oxa-Michael reaction took place the aldolization was completely inhibited by the coordinating pyridine.

Having identified $\mathrm{Cu}$ (isobutyrate) ${ }_{2}$ as the best catalyst for the aldolization, we subsequently applied the conditions of entry 9 to other aldehydes and ketoacids relevant in the context of natural products synthesis (Scheme 2).

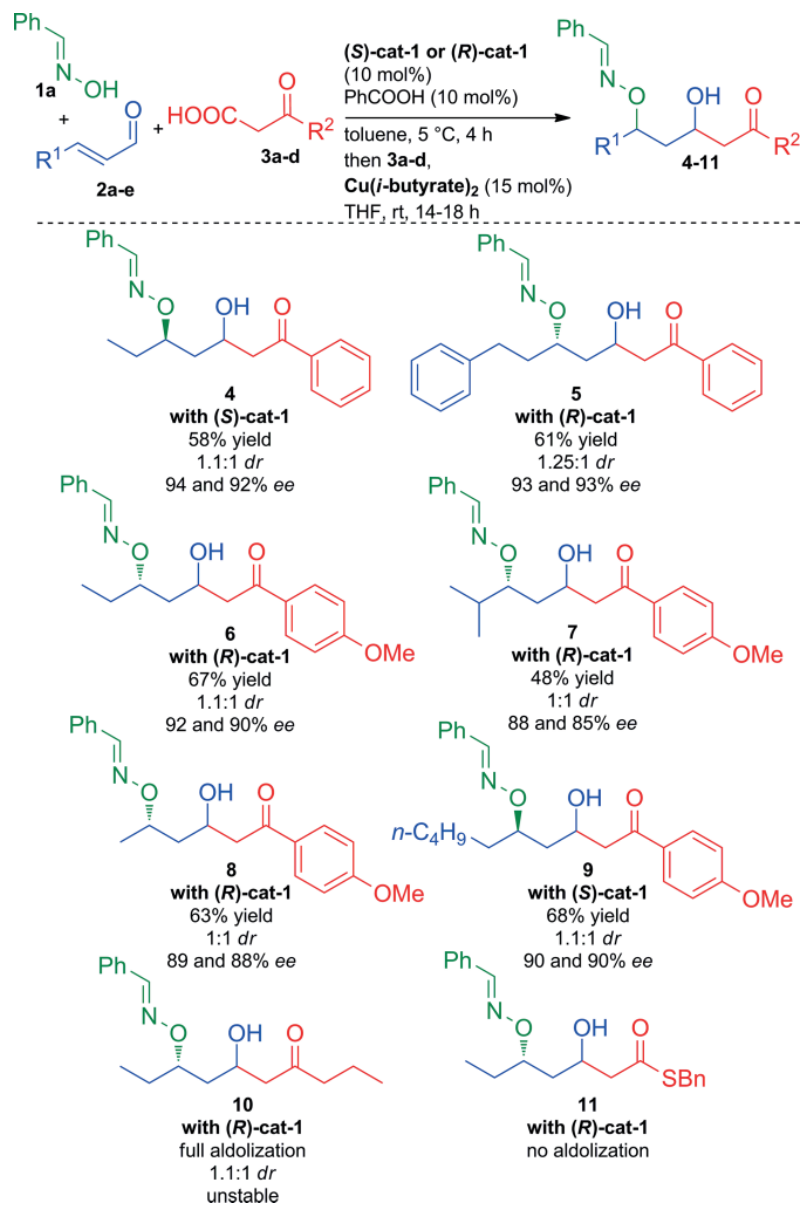

Scheme 2. Scope of the multi-catalytic oxa-Michael/aldolization.

Gratifyingly, the reaction tolerated various substitution patterns on the starting $\alpha, \beta$-unsaturated aldehydes. Different branched, short linear or long aliphatic chains, as well as phenyl-substituted ones, provided the final products with equal efficiency. Oxa-Michael/aldolization products 4-9 were formed in 48 to $68 \%$ yield, $1: 1$ to $1.25: 1 d r$ and 85 to $94 \%$ ee. Besides 3-oxo-3-phenylpropanoic acid (3a), electron-rich $p$-OMe aromatic of great synthetic potential also formed the expected alcohols 6-9 in good yield and enantiocontrol. The use of an aliphatic ketoacid also provided a good reactivity in the aldoli- zation forming compound 10. However, it was found that the final adduct suffered from poor stability preventing its isolation from the crude reaction mixture. Finally, thioester $\mathbf{3 d}$ did not provide any reactivity in the aldolization.

In order to highlight the synthetic potential of our approach, we decided to focus on the synthesis of (+)-yashabushitriol. This natural diarylheptanoid was isolated from alnus sieboldiana flowers. ${ }^{[14]}$ Its 1,3,5-triol structure has exalted the curiosity of the synthetic community and for now, four synthetic routes have been reported for its preparation. ${ }^{[15]}$ However, the challenge associated with the creation of the three alcohol functions has led to its enantioselective elaboration in lengthy 9 to 11 steps sequences.

Retrosynthetic disconnection of (+)-yashabushitriol following our approach would provide a highly convergent assembly from oxime $\mathbf{1} \mathbf{a}$, enal $\mathbf{2} \mathbf{b}$ easily prepared in one step ${ }^{[16]}$ and ketoacid 3a (Scheme 3).
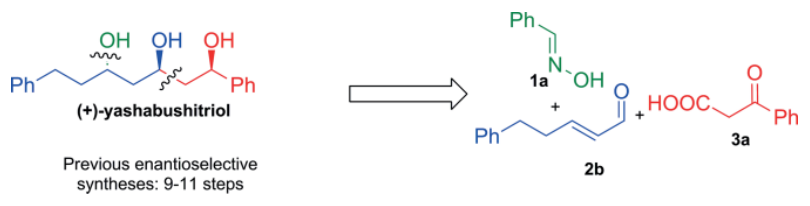

Scheme 3. Retrosynthetic analysis of (+)-yashabushitriol.

Thanks to our bi-catalytic multi-component protocol, 5 could be formed in 61\% yield, 1.25:1 dr and 93\% ee (Scheme 4). Direct simultaneous reduction of both oxime and ketone functions using $\mathrm{Pd}(\mathrm{OH})_{2} / \mathrm{C}$ provided the shortest route to the $(+)$-yashabushitriol scaffold 13. However, all our efforts to separate the mixture of diastereomers obtained through this two steps sequence failed.

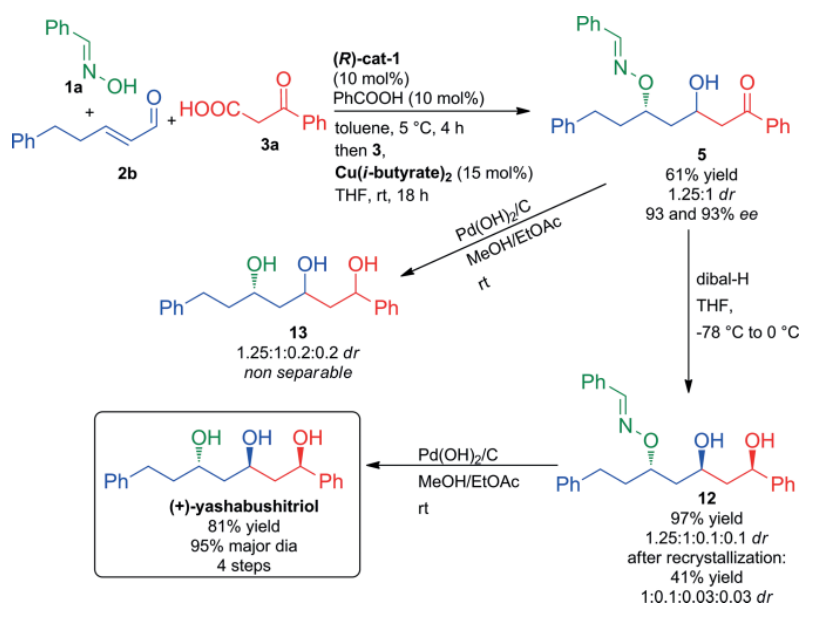

Scheme 4. Concise (+)-yashabushitriol synthesis.

Alternatively, chemoselective reduction of the ketone ${ }^{[17]}$ enabled the separation of the major diastereomer from the obtained crude mixture. As a result, 12 could be isolated in $41 \%$ yield after recrystallization (1:0.1:0.03:0.03 dr). Final palladium promoted hydrogenolysis of the oxime afforded the expected (+)-yashabushitriol in $81 \%$ yield ( $95 \%$ of the major dia). As a 
result, this global 4 steps sequence constitutes the shortest enantioselective route to date towards this natural 1,3,5-triol.

To conclude, by combining mutually compatible amino- and copper-catalysts we have been able to develop a new threecomponent oxa-Michael/aldolization sequence. This eco-compatible approach enables the enantioselective condensation of oximes and ketoacids on central $\alpha, \beta$-unsaturated aldehydes. Control of the stereochemistry by the organocatalyst enabled the formation of the corresponding adducts with excellent enantiomeric excesses (85-94\% ee). Even though the levels of diastereocontrol remain low, we have demonstrated that postfunctionalization could enable the isolation of the major diastereomer.

Thanks to the strategic one-pot assembly of these three building blocks, considerable shortcuts were obtained in the preparation of 1,3,5-triols. These synthetic economies were demonstrated in the shortest synthesis to date of $(+)$-yashabushitriol.

We are now focusing our efforts on improving reaction efficiency through the use of chiral copper complexes ${ }^{[18]}$ and applying other adducts to natural products synthesis.

\section{Acknowledgments}

The Centre National de la Recherche Scientifique (CNRS) and the Aix-Marseille Université are warmly acknowledged for financial support. All technical staff from Aix-Marseille Spectropole are acknowledged for their support as well as Marion Jean and Nicolas Vanthuyne for chiral HPLC analysis.

Keywords: Aldolization - Copper · Multicatalysis Organocatalysis - Polyketides

[1] a) D. O'Hagan, The Polyketide Metabolites; Ellis Horwood: Chichester, 1991; b) J. Rohr, Angew. Chem. Int. Ed. 2000, 39, 2847; Angew. Chem. 2000, 112, 2967; c) A. M. P. Koskinen, K. Karisalmi, Chem. Soc. Rev. 2005, $34,677$.

[2] For general reviews on polyols synthesis: a) T. Oishi, T. Nakata, Synthesis 1990, 8, 635; b) J. Staunton, K. J. Weissman, Nat. Prod. Rep. 2001, 18, 380; c) S. E. Bode, M. Wolberg, M. Muller, Synthesis 2006, 4, 557; d) B. Schetter, R. Mahrwald, Angew. Chem. Int. Ed. 2006, 45, 7506; Angew. Chem. 2006, 118, 7668; e) D. Herkommer, B. Schmalzbauer, D. Menche, Nat. Prod. Rep. 2014, 31, 456; f) A.-M. R. Dechert-Schmitt, D. C. Schmitt, X. Gao, T. Itoh, M. J. Krische, Nat. Prod. Rep. 2014, 31, 504; g) J. Feng, Z. A. Kasun, M. J. Krische, J. Am. Chem. Soc. 2016, 138, 5467; h) P. Kumar, D. Tripathi, B. M. Sharma, N. Dwivedi, Org. Biomol. Chem. 2017, 15, 733.

[3] For general reviews on catalytic aldolization, see: a) B. M. Trost, C. S. Brindle, Chem. Soc. Rev. 2010, 39, 1600; b) Y. Yamashita, T. Yasukawa, W. J. Yoo, T. Kitanosono, S. Kobayashi, Chem. Soc. Rev. 2018, 47, 4388.

[4] For a recent review, see: C. Sperandio, J. Rodriguez, A. Quintard, Org. Biomol. Chem. 2020, 18, 1025.

[5] a) N. S. Chowdari, D. B. Ramachary, A. Cordova, C. F. Barbas III, Tetrahedron Lett. 2002, 43, 9591; b) B. J. Albert, Y. Yamaoka, H. Yamamoto, Angew. Chem. Int. Ed. 2010, 49, 2747; Angew. Chem. 2010, 122, 2807; c) B. J. Albert, Y. Yamaoka, H. Yamamoto, Angew. Chem. Int. Ed. 2011, 50 , 2610; Angew. Chem. 2011, 123, 2658; d) J. Saadi, M. Akakura, H. Yamamoto, J. Am. Chem. Soc. 2011, 133, 14248; e) P. B. Brady, H. Yamamoto, Angew. Chem. Int. Ed. 2012, 51, 1942; Angew. Chem. 2012, 124, 1978; f) Y. Shimoda, T. Kubo, M. Sugiura, S. Kotani, M. Nakajima, Angew. Chem.
Int. Ed. 2013, 52, 3461; Angew. Chem. 2013, 125, 3545; g) L. Lin, K. Yamamoto, H. Mitsunuma, Y. Kanzaki, S. Matsunaga, M. Kanai, J. Am. Chem. Soc. 2015, 137, 15418; h) S. Kotani, K. Kai, Y. Shimoda, H. Hu, S. Gao, M. Sugiura, M. Ogasawara, M. Nakajima, Chem. Asian J. 2016, 11, 376; i) Y. Hayashi, T. Saitoh, H. Arase, G. Kawauchi, N. Takeda, Y. Shimasaki, I. Sato, Chem. Eur. J. 2018, 24, 4909.

[6] a) Y. Lu, I. S. Kim, A. Hassan, D. J. Del Valle, M. J. Krische, Angew. Chem. Int. Ed. 2009, 48, 5018; Angew. Chem. 2009, 121, 5118; b) X. Gao, H. Han, M. J. Krische, J. Am. Chem. Soc. 2011, 133, 12795; c) A. Hassan, I. A. Townsend, M. J. Krische, Chem. Commun. 2011, 47, 10028; d) A. Quintard, J. Rodriguez, Org. Lett. 2019, 21, 453.

[7] For work related to one-pot organocatalyzed intermolecular aza-Michael/Mannich, see: J. Vesely, I. Ibrahem, R. Rios, G.-L. Zhao, Y. Xu, A. Córdova, Tetrahedron Lett. 2007, 48, 2193 and references cited herein.

[8] For the organocatalyzed addition of oximes to $\alpha$-, $\beta$-unsaturated aldehydes, see: a) S. Bertelsen, P. Dinér, R. L. Johansen, K. A. Jørgensen, J. Am. Chem. Soc. 2007, 129, 1536; b) N. R. Andersen, S. G. Hansen, S. Bertelsen, K. A. Jørgensen, Adv. Synth. Catal. 2009, 351, 3193. For other related enantioselective Oxa-Michael addition, see: c) C. D. Vanderwal, E. N. Jacobsen, J. Am. Chem. Soc. 2004, 126, 14724; d) D. B. Ramachary, R. Mondal, Tetrahedron Lett. 2006, 47, 7689; e) T. Kano, Y. Tanaka, K. Maruoka, Tetrahedron 2007, 63, 8658; f) A. Carlone, G. Bartoli, M. Bosco, F. Pesciaioli, P. Ricci, L. Sambori, P. Melchiorre, Chem. Eur. J. 2007, 13, 5492; g) A. Carlone, G. Bartoli, M. Bosco, F. Pesciaioli, P. Ricci, L. Sambri, P. Melchiorre, Eur. J. Org. Chem. 2007, 5492; h) A. Quintard, A. Alexakis, Chem. Commun. 2011, 47, 7212; i) J. Wenga, L.-J. Huang, L. Long, L.-Y. Xu, G. Lu, Tetrahedron Lett. 2016, 57, 2554; j) F. Chen, H.-X. Ren, Y. Yang, S.-P. Ji, Z.-B. Zhang, F. Tian, L. Peng, L.-X. Wang, Chirality 2017, 29, 369.

[9] For selected reviews on decarboxylative aldolization reactions, see: a) Y. Pan, C.-H. Tan, Synthesis 2011, 13, 2044; b) Z. L. Wang, Adv. Synth. Catal. 2013, 355, 2745; c) S. Nakamura, Org. Biomol. Chem. 2014, 12, 394; d) S. Mao, K. Chen, G. Yan, D. Huang, Eur. J. Org. Chem. 2020, https://doi.org/ 10.1002/ejoc.201901605.

[10] For general reviews on multicatalysis, see: a) A. E. Allen, D. W. C. MacMillan, Chem. Sci. 2012, 3, 633; b) Z. Du, Z. Shao, Chem. Soc. Rev. 2013, 42, 1337; c) S. M. Inamdar, V. S. Shinde, N. T. Patil, Org. Biomol. Chem. 2015, $13,8116$.

[11] a) G. Lalic, A. D. Aloise, M. D. Shair, J. Am. Chem. Soc. 2003, 125, 2852; b) A. Quintard, J. Rodriguez, Chem. Commun. 2015, 51, 9523; c) A. Quintard, J. Rodriguez, Chem. Eur. J. 2015, 21, 14717; d) A. Quintard, J. Rodriguez, ACS Catal. 2017, 7, 5513; e) A. Ricucci, J. Rodriguez, A. Quintard, Eur. J. Org. Chem. 2018, 3697; f) A. Quintard, J. Rodriguez, Chimia 2018, 72, 580; g) A. Quintard, C. Sperandio, J. Rodriguez, Org. Lett. 2018, 20, 5274; h) C. Sperandio, G. Quintard, J. V. Naubron, M. Giorgi, M. Yemloul, J.-L. Parrain, J. Rodriguez, A. Quintard, Chem. Eur. J. 2019, 25, 15098.

[12] For early examples of organocatalytic processes, see: a) K. Rohr, R. Mahrwald, Org. Lett. 2011, 13, 1878; b) Y. Zheng, H.-Y. Xiong, J. Nie, M.-Q. Hua, J.-A. Ma, Chem. Commun. 2012, 48, 4308; c) F. Zhong, W. Yao, X. Dou, Y. Lu, Org. Lett. 2012, 14, 4018; d) H. Y. Bae, J. H. Sim, J.-W. Lee, B. List, C. E. Song, Angew. Chem. Int. Ed. 2013, 52, 12143; Angew. Chem. 2013, 125, 12365.

[13] Total lack of diastereocontrol had previously been observed in the onepot addition of grignard reagents see reference [8b].

[14] T. Hashimoto, M. Tori, Y. Asakawa, Chem. Pharm. Bull. 1986, 34, 1846.

[15] a) K. S. Feldman, R. E. Simpson, Tetrahedron Lett. 1989, 30, 6985; b) M. Miyashita, M. Hoshino, A. Yoshikoshi, Chem. Lett. 1990, 19, 791; c) Z. A. Fang, G. J. Clarkson, M. Wills, Tetrahedron Lett. 2013, 54, 6834; d) G. He, Y. Wang, C. Lai, W. Li, R. Hong, Sci. China. Chem. 2016, 59, 1197.

[16] A. Bouisseau, M. Gao, M. C. Willis, Chem. Eur. J. 2016, 22, 15624.

[17] a) S. I. Kiyooka, H. Kuroda, Y. Shimasaki, Tetrahedron Lett. 1986, 27, 3009; b) B. Kang, J. Mowat, T. Pinter, R. Britton, Org. Lett. 2009, 11, 1717.

[18] a) S. Orlandi, M. Benaglia, F. Cozzi, Tetrahedron Lett. 2004, 45, 1747; b) D. Magdziak, G. Lalic, H. M. Lee, K. C. Fortner, A. D. Aloise, M. D. Shair, J. Am. Chem. Soc. 2005, 127, 7284; c) K. C. Fortner, M. D. Shair, J. Am. Chem. Soc. 2007, 129, 1032; d) C. Sperandio, J. Rodriguez, A. Quintard, Chem. Sci. 2020, 11, 1629. 